\title{
Pengaruh Metode Latihan Drill Terhadap Ketepatan Pukulan Backhand Clear Pada Siswa Ekstrakurikuler Bulutangkis SMK Negeri 3 Jepara
}

\author{
Riza Indra Dwijaya ${ }^{1}$, Galih Dwi Pradipta ${ }^{2}$, Setiyawan ${ }^{3}$ \\ Universitas PGRI Semarang, Jl. Sidodadi Timur No 24 - Dr. cipto, Semarang, \\ E-mail : rezaindra@gmail.com
}

\begin{abstract}
This research is based on the lack of ability to roll the backhand of badminton extracurricular students at SMK Negeri 3 Jepara because the backhand style is still difficult and they are not used to the variation of punch training and have never been given special training by the coach. The purpose of this study was to determine all the effects of training exercises on the accuracy of the back strokes of badminton extracurricular students at SMK Negeri 3 Jepara. This research was conducted with a quantitative approach. The design of this study is a Quasi Experiment with the method of The Untreated Control Group Design with Pretest and Posttest with data retrieval using tests. The population in this study was 30 students and the sample was taken by purposive sampling or with certain provisions as many as 16 students and divided into 2 groups, namely group 1 as treatment recipient and group 2 without treatment. The data technique uses the treatment of the drill training method. The data analysis technique used in this study was the prerequisite test, including the normality test, homogeneous test, and hypothesis testing. The results of the study indicate that the training method affects the accuracy of rolling backhand badminton extracurricular students of SMK Negeri 3 Jepara from group 1 with an average of 22.5 and a value of 10.828>t table 2.145 and a significance value of $0.000<0.05$, with a percentage increase of 13 , $47 \%$, while for group 2 without treatment with an average of 19,625 which is only $8.47 \%$ with an average difference of 3,875 posttest. The anatomical results of the training method also have an effect on increasing the students' body movements, because the body stimulates the body with fast movements so that the student's body becomes accustomed to doing backhand clear strokes. It can be rejected that the hypothesis h1 is accepted there is an effect of the drill training method on the accuracy of rolling backhand clear at SMK Negeri 3 Jepara is accepted.
\end{abstract}

Keywords: Keywords: backhand clear, drill practice, accuracy

\begin{abstract}
Abstrak
Penelitian ini di latar belakangi oleh kurangnya kemampuan pukulan backhand clear siswa ekstrakurikuler bulutangkis SMK Negeri 3 Jepara dikarenakan pukulan backhand dianggap masih sulit dan belum terbiasa juga kurangnya variasi latihan pukulan dan belum pernah diberikan latihan secara khusus oleh pelatih. Tujuan penelitian ini untuk mengetahui seberapa besar pengaruh latihan drill untuk ketepatan pukulan backhand clear siswa ekstrakuriler bulutangkis SMK Negeri 3 Jepara. Penelitian ini dilakukan dengan pendekatan kuantitatif. Desain penelitian ini adalah Quasi Experimen dengan metode The Untreated Control Group Design with Pretest and Posttest dengan pengambilan data menggunakan tes. Populasi dalam penelitian ini adalah 30 siswa dan diambil sampel dengan purposive sampling atau dengan ketentuan tertentu sebanyak 16 siswa dan dibagi menjadi 2 kelompok yaitu kelompok 1 sebagai penerima treatment dan kelompok 2 tanpa treatment. Teknik pengumpulan data menggunakan treatment metode latihan drill. Teknik analisis data dalam penelitian menggunakan uji prasyarat antara lain uji normalitas, uji homogeny, dan uji hipotesis. Hasil dari penelitian menunjukan bahwa metode latihan drill berpengaruh terhadap ketepatan pukulan backhand clear siswa ekstrakurikuler bulutangkis SMK Negeri 3 Jepara dari kelompok 1 dengan rata-rata 22,5 dan nilai $t_{\text {hitung }} 10,828>\mathrm{t}_{\text {tabel }} 2,145$ dan nilai signifikansi $0,000<0,05$, dengan peningkatan presentase $13,47 \%$, sedangkan untuk kelompok 2 tanpa perlakuan dengan rata-rata 19,625 yang hanya sebesar $8,47 \%$ dengan selisih rata-rata posttest 3,875 . Hasil secara anatomi metode latihan drill juga berpengaruh dalam peningkatan pergerakan tubuh siswa, karena rangsangan tubuh dengan gerakan cepat sehingga gerak tubuh siswa menjadi terbiasa dalam melakukan pukulan backhand clear.Dapat disimpulkan bahwa hipotesis h1 diterima yaitu ada pengaruh metode latihan drill terhadap ketepatan pukulan backhand clear SMK Negeri 3 Jepara diterima...
\end{abstract}

Kata kunci: backhand clear, latihan drill, ketepatan 


\section{PENDAHULUAN}

Bulutangkis merupakan salah satu olahraga yang terkenal di Indonesia. Olahraga ini menarik minat berbagai kelompok umur, berbagai tingkat keterampilan, dan pria maupun wanita memainkan olahraga ini di dalam atau di luar ruangan untuk rekreasi juga sebagai ajang persaingan. Bulutangkis atau badminton adalah suatu olahraga raket yang dimainkan oleh dua orang atau dua pasangan yang saling berlawanan. Mirip dengan tenis, bulutangkis bertujuan memukul bola permainan shuttlecock melewati jaring agar jatuh di bidang permainan lawan yang sudah ditentukan dan berusaha mencegah lawan melakukan hal yang sama ( Hartini, 2012 : 17 )Pukulan Clear atau lob adalah salah satu teknik dalam bermain bulutangkis, menurut dropshot, smash, drive atau mendatar dan pengembalian servis. Menurut Tohar ( Pradana, 2012: 3) dapat dilakukan dengan 2 cara yaitu overhead lob pukulan lob yang dilakukan dari atas kepala dengan cara menerbangkan shuttlecock melambung ke arah belakang. Kedua adalah underhand lob yaitu pukulan dari bawah yang dilakukan dengan memukul shuttlecock yang berada di bawah badan dilambungkan tinggi. Menurut Pradana (2012:3) pukulan backhand clear adalah pukulan tinggi jauh ke bagian belakang lapangan lawan yang dilakukan dari sisi tubuh yang tidak dominan pada saat shuttlecock berada diatas ketinggian kepala.

Metode latihan Drill adalah satu kegiatan yang dilakukan hal yang sama, berulang-ulang secara sungguh-sungguh dengan tujuan memperkuat suatu asosiasi atau menyempurnakan suatu keterampilan agar menjadi bersifat permanen. Ciri pengulangan yang berkali-kali dari sesuatu yang sama. Seperti yang diungkapkan oleh Bompa ( Wiratama, 2016:5 ) bahwa prinsip latihan memiliki peranan penting terhadap aspek fisiologis dan psikologis olahragawan, dengan memahami prinsip-prinsip latihan akan mendukung upaya dalam meningkatkan kualitas latihan. Keberhasilan penguasaan teknik pukulan dalam permainan bulutangkis diperoleh dari latihan yang benar teratur serta didukung oleh program latihan yang tepat. Oleh karena itu, dengan modal berlatih tekun, disiplin, dan terarah di bawah bimbingan pelatih yang berkualitas, dapat menguasai berbagai teknik dasar bermain bulutangkis secara benar.

Berdasarkan data hasil observasi peneliti dari test yang dilakukan saat kegiatan latihan rutin menggunakan model latihan umpan shuttlecock ke arah pemain sebanyak 10 kali pukulan dengan arah penempatan secara acak dapat disimpulkan kemampuan ketepatan pukulan terutama ketepatan dalam melakukan pukulan backhand clear yang dilakukan oleh siswa peserta ektrakurikuler bulutangkis SMK Negeri 3 Jepara hanya terdapat 5 siswa dari 30 jumlah keseluruhan siswa peserta ektrakurikuler bulutangkis SMK Negeri 3 Jepara yang dapat menguasai pukulan backhand clear, sedangkan untuk yang lainnya dinilai masih kurang dan masih belum bisa mengusai pukulan backhand dengan baik dan benar, masalah yang dihadapi ketika melakukan pukulan backhand clear diantaranya shuttlecock yang tidak tepat mengenai raket saat dipukul dan kemudian shuttlecock tidak bisa terbang melewati net. 
Sedangkan untuk metode latihan drill tidak pernah diberikan secara khusus dan masih kurang, dikarenakan pelatih hanya sedikit memberikan pelatihan teknik dasar secara umum, kendala lain adalah terhalang oleh durasi waktu latihan ektrakurikuler yang hanya berdurasi 1 jam, sehingga tidak jarang siswa hanya berlatih secara mandiri dan hanya mengandalkan kemampuan yang dimilikinya.

Oleh karena itu berdasarkan latar belakang yang telah dikemukakan di atas, maka peneliti tertarik melakukan penelitian dengan judul "Pengaruh Latihan Drill Terhadap Ketepatan Pukulan Backhand Clear Pada Siswa Ekstrakurikuler Bulutangkis SMK Negeri 3 Jepara”.

\section{METODE}

Metode penelitian ini adalah penelitian kuantitatif dengan Desain yang digunakan dalam penelitian ini adalah quasi experiment atau ekeprimen semu dengan metode The Untreated Control Group Design with Pretest and Posttest.

Menurut Suryana $(2010,20)$ menyatakan bahwa penelitian untuk menguji apakah efektif apa tidaknya variabel, penelitian eksperimen untuk menguji hipetesis secara ketat, penelitian eksperimen biasa dilakukan untuk bidang bersifat eksas, sedangkan untuk sosial digunakan metode survei, deskriptif ,dan historis.

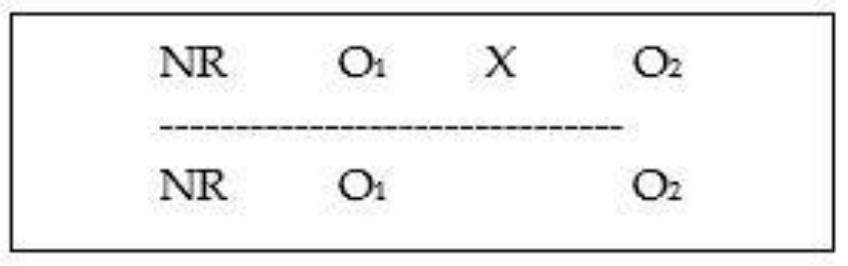

Gambar 1. Desain The Untreated Control Group Design with Pretest and Posttest

Sumber : Hastjarjo ( 2016: 25 )

NR : Kelompok A dan Kelompok B

O1 : Pretest awal, Tes dilakukan sebelum subjek mendapatkan perlakuan treatment.

$\mathrm{X} \quad$ : Pemberian pendekatan perlakuan latihan metode latihan backhand clear

O2 : Posttest, Tes dilakukan setelah subjek mendapat Perlakuan. 
Penelitian mengambil sebagian populasi dengan teknik purposive sampling. Menurut Sugiyono (Wiratama, 2015: 44) purposive sampling teknik pengambilan sampel dengan ketentuan tertentu. Setelah itu sampel siswa atau pretest sebelum diberikan pendekatan perlakuan yaitu, setelah itu peneliti memberikan pendekatan perlakuan latihan kepada sampel dan setelah peneliti memberikan pendekatan perlakuan dilakukan posttest atau test untuk menentukan dan membandingkan hasil yang diperoleh sebelum dan sesudah melakukan pendekatan perlakuan.

Dalam penelitian ini jumlah seluruh anggota ekstrakurikuler bulutangkis SMK Negeri 3 Jepara berjumlah 31 dan mengambil sampel sebanyak 16 siswa dan dipilih dengan kriteria meliputi : a. Anggota ekstrakurikuler bulutangkis SMK Negeri 3 Jepara. b. Daftar keaktifan latihan minimal $70 \%$. c. Belum mahir mengusai pukulan backhand. Alasan menggunakan sampel dikarenakan latihan di ekstrakurikuler terbatas oleh, waktu, tempat, biaya, dan tenaga maka jumlah sampel yang digunakan dalam penelitian ini berjumlah 16 pemain. Populasi dan sampel yang digunakan dalam penelitian kali ini adalah seluruh siswa anggota ekstrakurikuler bulutangkis SMK Negeri 3 Jepara.

Menurut Suharsimi (Santoso, 2011: 36 ) menyatakan bahwa instrument merupakan alat bantu yang digunakan oleh peneliti dalam melakukan kegiatan untuk mengumpulkan data agar kegaiatan dapat berjalan mudah dan sistematis. Data yng digunakan dalam penelitian ini adalah pretest yang diperoleh sampel dalam melakukan tes backhand clear sebelum diberi treathment, sedangkan data posttest diperoleh dari sampel setelah diberikan treathment latihan drill.

Data yang diambil. Untuk itu dalam penelitian ini akan diambil sebelum dan sesudah melakukan test dan dilakukan pengolahan analisis data secara statistik. Adapun langkah-langkah dalam melakukan analisis data adalah : Uji Normalitas, Uji Homogen, dan Uji Hipotesis.

\section{HASIL DAN PEMBAHASAN}

Subjek Penelitian ini adalah siswa peserta ekstrakurikuler bulutangkis SMK Negeri 3 Jepara yang berjumlah 16 siswa. Penelitian ini dilaksanakan di Gedung PGRI Kabupaten Jepara. Waktu untuk melakukan penelitian dilaksanakan pada tanggal 26 September 2020 - selesai. Pretest diambil pada tanggal 26 September 2020 dan posttest diambil pada tanggal 21 November 2020. Treatment dilakukan sebanyak 12 kali pertemuan dengan frekuensi latihan 2 ( dua ) kali dalam seminggu, yaitu pada hari Selasa dan Sabtu.

Hasil pretest diperoleh nilai minimal $=7,0$, nilai maksimal $=13,0$, rata-rata $($ mean $)=10,12$, sedangkan untuk post-test nilai minimal $=19,0$, nilai maksimal $=26,0$, dan rata-rata $($ mean $)=22,5$. Hasil selengkapnya disajikan dalam tabel berikut : 
Tabel 1. Hasil Pre-test dan Post-test kelompok 1 ( treatment)

\begin{tabular}{lll}
\hline No. Subjek & pre-test & Post-test \\
\hline 1 & 8 & 26 \\
\hline 2 & 7 & 19 \\
\hline 3 & 8 & 19 \\
\hline 4 & 13 & 24 \\
\hline 5 & 11 & 21 \\
\hline 6 & 13 & 22 \\
\hline 7 & 10 & 25 \\
\hline 8 & 11 & 24 \\
\hline Mean & 10.125 & 22.5 \\
\hline Minimal & 8,0 & 19,0 \\
\hline Maksimal & 13,0 & 26,0 \\
\hline
\end{tabular}

Gambar 2. Diagram pre-test dan post-test kelompok 1 (treatment)

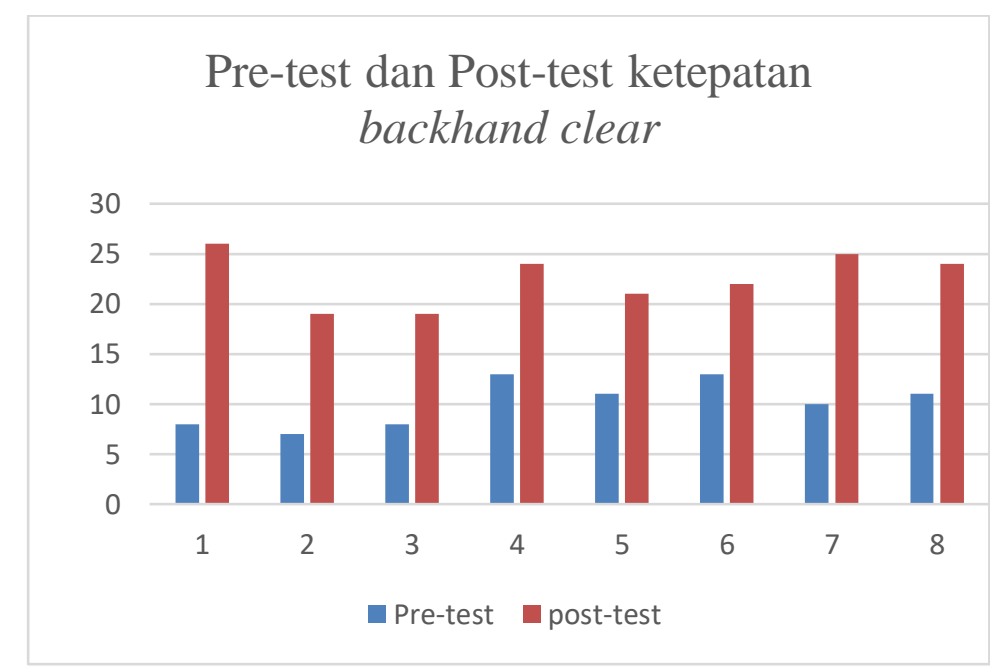

Adapun rata-rata hasil pre-test dan post-test ketepatan pukulan backhand clear siswa ektrakurikuler SMK Negeri 3 Jepara sebagai berikut: 


\section{Gambar 3. Diagram rata-rata kelompok 1 (treatment)}

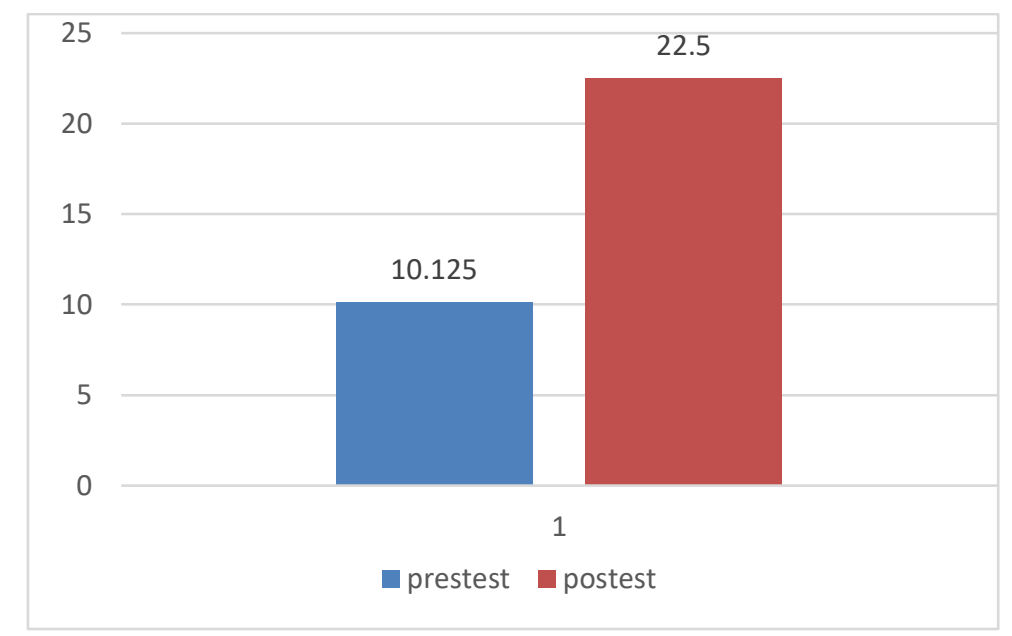

\section{Uji Normalitas}

Data menggunakan penghitungan rumus Kolmogorov-Smirnov hasilnya dapat diuraikan sebagai berikut :

Tabel 2. Uji Normalitas hasil penelitian

\begin{tabular}{llll}
\hline test & P & Sig. & Keterangan \\
\hline pre-test & 0,164 & 0,05 & Normal \\
\hline post-test & 0,200 & 0,05 & Normal
\end{tabular}

Dari data diatas dapat disimpulkan bahwa, hasil uji normalitas pretest sebesar 0,164, karena nilai signifikasi yang diperoleh lebih besar dari $o$ yaitu 0,05 , maka hasil data pretest yang diambil dari sampel tersebut berdistribusi normal. Nilai signifikasi yang diperoleh dari posttest adalah 0,200, karena nilai signifkasi yang diperoleh dari data posttest lebih besar dari $o$, maka hasil data pretest yang diambil dari sampel tersebut berdistribusi normal. Karena dapat dilihat semua data pretest dan posttest $>0,05$, maka variabel pretest dan posttest dapat dikatakan normal.

\section{Uji Hipotesis}

Hasil analisis yang menunjukan perbedaan yang signifikan maka latihan drill memberikan pengaruh terhadap ketepatan pukulan backhand clear siswa ekstrakurikuler bulutangkis SMK Negeri 3 Jepara. kesimpulan penelitian dinyatakan signifikan apabila $t_{\text {hitung }}>\mathrm{t}_{\text {tabel }}$ dan nilai sig. lebih kecil dari 0,05 (sig $<0,05$ ). Berdaarkan hasil analisis dapat dilihat dalam tabel berikut : 
Tabel 3. Uji-t hasil pretest dan posttest kelompok 1

\begin{tabular}{lllllll}
\hline test & mean & $\mathrm{t}_{\text {hitung }}$ & $\mathrm{t}_{\text {tabel }}$ & $\mathrm{sig}$ & selisih & $\%$ \\
\cline { 1 - 2 } pretest & 10.125 & \multirow{2}{*}{10,828} & 0,145 & 0,000 & 10,375 & $13,47 \%$ \\
\cline { 1 - 1 } & 22.5 & & & & & \\
\hline
\end{tabular}

Dari hasil uji t dapat dilihat bahwa $\mathrm{t}_{\text {hitung }} 10,828$ dan $\mathrm{t}_{\text {tabel }} 0,145$, dan nilai signifikasi 0,000 , oleh karena itu nilai $\mathrm{t}_{\text {hitung }} 10,828>\mathrm{t}_{\text {tabel }} 0,145$, dan nilai signifikasi $0,000<0,05$, Jadi dengan demikian terdapat perbedaan yang signifikan saat melakukan pretest dan posttest. Hasil dapat dilihat dalam tabel.

Tabel 4. Uji Hipotesis perbandingan kelompok 1 dan 2

Sumber : Diolah oleh penulis

\begin{tabular}{|c|c|c|c|c|c|c|}
\hline Test & mean & $\%$ & thitung & ttabel & Sig & Selisih \\
\hline $\begin{array}{l}\text { kelompok } \\
1\end{array}$ & 22.5 & $13,47 \%$ & 10,127 & 2,145 & 0,141 & 3,875 \\
\hline $\begin{array}{l}\text { kelompok } \\
2\end{array}$ & 19.625 & $8,74 \%$ & & & & \\
\hline
\end{tabular}

Berdasarkan tabel diatas dari perhitungan uji-t dapat diketahui perbandingan posttest kelompok 1 dan kelompok 2, dari tabel tersebut dapat dilihat bahwa $t_{\text {hitung }}$ sebesar 10,127 dan $\mathrm{t}_{\text {tabel }}$ sebesar 1,145, besar signifikasi 0,407. Maka hasil analisis menunjukan bahwa metode latihan drill berpengaruh dalam ketepatan pukulan backhand clear, dan rata-rata ( mean) posttest. Dengan selisih rata-rata 3,875. Dengan demikian h1 yang berbunyi "Terdapat pengaruh latihan drill terhadap ketepatan backhand clear pada siswa ekstrakurikuler bulutangkis SMK Negeri 3 Jepara", diterima.

Dari hasil pengamatan secara anatomi metode latihan drill juga berpengaruh dalam peningkatan pergerakan tubuh siswa, dalam melakukan pukulan backhand clear pergerakan tubuh terutama tangan dalam melakukan menjadi lebih terbiasa, hal itu dikarenakan latihan drill dilakukan secara berulangulang sehingga menciptakan rangsangan pada tubuh secara otomatis dengan gerakan yang cepat seperti menurut Suharso ( Wiratama, 2016:15 ) melakukan metode drill latihan terus menerus akan ada hubungan antara rangsangan dan jawaban secara otomatis.

\section{KESIMPULAN}

Berdasarkan analisis data, deskripsi, pembahasan dan pengujian penelitian dapat disimpulkan bahwa terdapat pengaruh yang signifikan dari metode latihan drill terhadap pukulan backhand clear siswa ekstrakurikuler bulutangkis SMK Negeri 3 Jepara sebesar 13,47\% dibandingkan dengan kelompok 2 tanpa perlakuan ( treatment) yang hanya sebesar 8,47\% dengan selisih rata-rata posttest 3,875 . 
Hasil dari pengamatan dari segi anatomi juga menunjukan bahwa metode latihan drill berpengaruh dalam peningkatan pergerakan tubuh siswa, dalam melakukan pukulan backhand clear pergerakan tubuh terutama tangan dalam melakukan menjadi lebih terbiasa, karena gerakan yang berulang-ulang ulang sehingga menciptakan rangsangan pada tubuh secara otomatis dengan gerakan yang cepat.

Metode latihan drill dikatakan efektif digunkan untuk melatih ketepatan pukulan backhand clear dalam permainan bulutangkis.

\section{DAFTAR PUSTAKA}

Hartini, M.J. 2012.“ Gedung Olah Raga Bulutangkis Yogyakarta. Skripsi. Yogyakarta : Universitas Negeri Yogyakarta. Tidak Diterbitkan.

Hastjarjo, T. 2019. "Rancangan Eksperimen-Kuasi Quasi-Experimnetal Design". Buletin Psikologi. 27(2) $187-203$.

Pradana, Aries. 2012. Tingkat Kecakapan Pukulan Backhand Overloab Mahasiswa IKK Bulutangkis I Jurusan PKLO FIK UNNES Tahun 2012. Skripsi. Semarang : Universitas Negeri Semarang. Tidak Diterbitkan.

Seko, S.K. 2011."Pengaruh Metode Latihan Drill Terhadap Peningkatan Kemampuan Passing Bawah Peserta Ekstrakurikuler Bola Voli Putri SMP Negeri 4 Gamping Sleman”. Skripsi. Yogyakarta : Universitas negeri Yogyakarta.

Suryana. 2010. Metodologi Penelitian Model Prakatis Penelitian Kuantitatif dan Kualitatif. Jakarta : Universitas Negeri Jakarta. 